\title{
CRIATIVIDADE E APRENDIZAGEM COLABORATIVA ATRAVÉS DA PRODUÇÃO DE REPRESENTAÇÕES GRÁFICAS DE SÍNTESE: UMA EXPERIÊNCIA COM ALUNOS DE ARTES VISUAIS
}

\section{CREATIVITY AND COLLABORATIVE LEARNING THROUGH THE PRODUCTION OF SYNTHESIS GRAPHIC REPRESENTATIONS: AN EXPERIENCE WITH VISUAL ARTS STUDENTS}

\author{
Waldeilson Paixão ${ }^{1}, \mathrm{Me}$ \\ Juliana Bueno ${ }^{2}$, Dra. \\ Rosane Obregon ${ }^{3}, \mathrm{Dr}^{\mathrm{a}}$ \\ Ana Lúcia Zandomenghi ${ }^{4}$, Dra
}

(1) Universidade Federal do Maranhão - UFMA e-mail: waldeilsonpaixao@gmail.com

(2) Universidade Federal do Paraná - UFPR e-mail:oieusouaju@gmail.com

(3) Universidade Federal do Maranhão - UFMA e-mail: antunesobregon@gmail.com

(4) Universidade Federal do Maranhão - UFMA e-mail: zandomeneghianalucia@gmail.com

Palavras-chave: pensamento visual, ensino, práticas coletivas

Esta pesquisa apresenta a aplicação de Representações Gráficas de Síntese (RGSs) para estimular a criatividade e favorecer o aprendizado colaborativo em sala de aula. RGSs são formas bidimensionais de representação visual que apoiam os conteúdos teóricos. Dessa maneira, o artigo traz um estudo qualitativo que fora aplicado com duas turmas de ensino médio-tecnológico, durante a condução de uma disciplina no curso de Artes Visuais, em um campus de um Instituto Federal. O objetivo foi estimular a criatividade dos estudantes e proporcionar a apreensão dos conteúdos da disciplina por meio da produção de RGSs, desenvolvidas de forma colaborativa. Os resultados indicaram que a utilização das RGSs em sala de aula foi uma forma criativa de engajar os estudantes na disciplina como também uma alternativa facilitadora no processo de ensino-aprendizagem. 


\section{$16^{\circ}$ \\ ERGODESIGN USIHC CINAHPA}

$16^{\circ}$ Ergodesign - Congresso Internacional de Ergonomia e Usabilidade de Interfaces Humano Tecnológica: Produto, Informações Ambientes Construídos e Transporte

$16^{\circ}$ USIHC - Congresso Internacional de Ergonomia e Usabilidade de Interfaces Humano Computador

CINAHPA | 2017 - Congresso Internacional de Ambientes Hipermídia para Aprendizagem.

Key-words: visual thinking, teaching, collective practices

This research presents the application of Graphic Representations of Synthesis (RGSs) to stimulate the creativity and to favor the collaborative learning in the classroom. RGSs are two-dimensional forms of visual representation that support theoretical content. In this way, the article brings a qualitative study that was applied with two classes of high-tech teaching, while conducting a course in the Visual Arts course, on a campus of a Federal Institute. The objective was to stimulate the students' creativity and to apprehend the contents of the discipline through the production of RGSs, developed in a collaborative way. The results indicated that the use of RGSs in the classroom was a creative way of engaging students in the discipline as well as a facilitating alternative in the teachinglearning process.

\section{Introdução}

Em cursos técnicos de Artes Visuais, a criatividade é uma competência necessária para que os estudantes possam desenvolver suas habilidades; produzir novas soluções para os desafios que são oferecidos em sala e para os que futuramente virão com o mercado de trabalho.

Os conhecimentos práticos são uma característica nesse formato de curso, e dessa maneira, estimulam o pensar criativo dos estudantes através de um aprendizado mais flexível. Vale salientar que, para a consolidação e aprendizagem adequada desses conhecimentos práticos, o conteúdo teórico é parte fundamental no processo, e assim deve ser encarado com igual importância.

Contudo, reter a atenção dos alunos durante um longo período de tempo, no formato tradicional hierárquico professor/aluno, especialmente nos conteúdos teóricos, configura-se como um desafio às práticas de ensino/aprendizagem. $\mathrm{O}$ cansaço e a distração dos alunos podem ser alguns pontos negativos deste formato, e a consequência disto, muitas das vezes, se apresenta na forma de uma compreensão fragmentada ou errônea dos conteúdos, prejudicando o sequenciamento das atividades e o processo de ensino/aprendizagem.

Autores ressaltam a necessidade de uma educação mais criativa (ALENCAR, 2007; BACHERT et al., 2011). Morais (2011), identifica culturas governamentais que realizaram revisões curriculares, para explorar novas formas que favoreçam o desenvolvimento das competências dos alunos.

É possível identificar algumas alternativas criativas que podem confrontar as dificuldades, facilitar as atividades em sala, e que estão mais alinhadas aos novos interesses na educação. Elas oferecem uma dinâmica mais atrativa na condução dos conteúdos Entre as alternativas identificadas estão as Representações Gráficas de Síntese (RGSs), que se constituem como um meio alternativo (e criativo) para que professor, alunos ou grupos de aluno possam refletir, discutir e produzir os conhecimentos de maneira mais estimulante. Assim, cria-se um ambiente propício para uma adequada assimilação por parte dos alunos envolvidos, de forma mais horizontal, onde os conceitos de compartilhamento, interação e cooperação também podem ser explorados.

RGSs são artefatos visuais cognitivos físicos produzidos por meio de técnicas de facilitação gráfica, como o Pensamento Visual, que visam representar (ou materializar) os conhecimentos apreendidos sobre um determinado assunto prédefinido. É uma produção que põe seu criador em uma posição de confronto com suas reflexões sobre o que fora abordado, e sobre o que é mais essencial a ser dito. Além disso, as RGSs são úteis para estimular a criatividade de quem as produz, uma vez que soluções devem ser encontradas para se conseguir representar o conteúdo da maneira mais criativa, atrativa e clara.

No contexto dos Institutos Federais (IFs), que compõem a Rede Federal de Educação Profissional, Científica e Tecnológica, alternativas como as RGSs podem ser de grande ajuda para a aplicação prática dos conhecimentos ora assimilados na teoria, isso porque tais instituições são focadas na capacitação técnica, como pode ser observado desde o seu surgimento, com as escolas de Aprendizes e Artífices, em 1909, até os dias atuais (PORTAL REDE FEDERAL, 2016).
Realização:

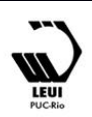




\section{$16^{\circ}$ \\ ERGODESIGN USIHC CINAHPA}

No caso de cursos onde a criatividade é bastante exigida, como em Artes Visuais, explorá-la é um requisito necessário para que o futuro técnico possa ter condições de desenvolver seu trabalho de maneira alinhada à sua formação. Porém, Bachert et al. (2011) fez um levantamento da produção científica sobre criatividade e educação e concluiu que, entre os estudos, o Ensino Médio está entre os níveis com menor número de estudos realizados. Logo, entende-se que a estratégia didática das RGSs descortina uma possibilidade de estimular a criatividade e oportunizar o aprendizado para as futuras práticas artísticas em cursos dessa natureza.

Assim, o estudo, aqui apresentado, teve como objetivo estimular a criatividade de estudantes e promover o ensino/aprendizagem de modo colaborativo por meio da produção de Representações Gráficas de Síntese (RGSs). O estudo foi realizado junto aos alunos do Instituto Federal de Educação, Ciência e Tecnologia do Maranhão (IFMA), Campus Centro Histórico.

Neste alinhamento introdutório, o artigo apresenta os conceitos relacionados à pesquisa; na sequência o método adotado com todo seu procedimento aplicado em sala de aula a partir da produção das RGSs. Por fim, são apresentados os resultados, conclusões e os desdobramentos futuros da pesquisa.

\section{Criatividade}

A criatividade é assunto de interesse de várias áreas do conhecimento, como Psicologia, Marketing, Design, Artes, Educação, etc. Defini-la é um dos desafios a serem vencidos face a grande quantidade de definições que há (MORAIS, 2011). Algumas discussões demostram que ela está relacionada à geração de ideias ou produtos originais em um dado contexto, com potencial para resolução de problemas do cotidiano. Outras ilustram mitos onde a criatividade está associada às características dos indivíduos como um potencial criador (MORAIS; ALMEIDA, 2016; MORAIS, 2011).

Alguns defendem que as artes são mais favoráveis à manifestação da criatividade (CROPLEY; $16^{\circ}$ Ergodesign - Congresso Internacional de Ergonomia e Usabilidade de Interfaces Humano Tecnológica: Produto, Informações Ambientes Construídos e Transporte

$16^{\circ}$ USIHC - Congresso Internacional de Ergonomia e Usabilidade de Interfaces Humano Computador

CINAHPA | 2017 - Congresso Internacional de Ambientes Hipermídia para Aprendizagem.

CROPLEY, 2009), enquanto que para outros (HOSSEINI, 2011), não mais que as Ciências. Morais (2011), diz que a criatividade é pertencente a qualquer contexto acadêmico ou pessoal, e que não se restringe ao contexto artístico. Longe dessa discussão sobre qual domínio de conhecimento é mais favorável à promoção da criatividade, as artes estão entre aquelas propícias ao fazer criativo.

Outra discussão fala que a criatividade é resultado de uma iluminação divina reservada a poucos escolhidos pela natureza. Um levantamento realizado por Bachert et al. (2011), demonstra que as pesquisas nacionais indicam que a criatividade no contexto educacional ainda é definida com base nesse senso comum. No entanto, sabe-se que mesmo aquele $1 \%$ de inspiração súbita e inexplicável, associada à genialidade, surge por meio de um lento percurso de trabalho, de persistência, de reavaliações e manutenção persistente do conhecimento no sentido objetivo (MORAIS, 2011). O mito da genialidade de um ser, isolado e capaz de produzir a criação súbita, ainda é uma barreira para que a criatividade não seja explorada corretamente em sala de aula (CROPLEY; CROPLEY, 2009).

Nos cursos de Artes, constata-se também esse mito. Como dito a pouco, e é consenso, a criatividade não é uma característica extraordinária ou super-humana; ela difere apenas em grau de pessoa para pessoa e florescerá dependendo do ambiente (ALENCAR, 2007). Pesquisas localizadas por Bachert et al. (2011), identificam que todas as pessoas possuem potencial criativo. Isso significa dizer que a criatividade pode ser ensinada e estimulada à grande maioria das pessoas, entendida como uma competência modificável, trazendo aspectos positivos (CROPLEY; CROPLEY, 2009).

Alencar (2007), identifica que o papel de uma base sólida de conhecimento, motivação e esforço são importantes para promover a criatividade nas pessoas. Para o autor, a criatividade não é algo do acaso, pode ser deliberadamente empregada, gerenciada e desenvolvida. Morais (2011), diz que, ao invés de se pensar no conceito de criatividade, é melhor pensar sobre o que requer a criatividade,

Realização:




\section{$16^{\circ}$ \\ ERGODESIGN USIHC CINAHPA}

$16^{\circ}$ Ergodesign - Congresso Internacional de Ergonomia e Usabilidade de Interfaces Humano Tecnológica: Produto, Informações Ambientes Construídos e Transporte

$16^{\circ}$ USIHC - Congresso Internacional de Ergonomia e Usabilidade de Interfaces Humano Computador

CINAHPA | 2017 - Congresso Internacional de Ambientes Hipermídia para Aprendizagem. logo, ser criativo, implica em alguns requisitos que podem ser operacionalizáveis, tais como: processos, motivação, personalidade, conhecimento, aptidões, olhar do outro.

Esses requisitos ampliam o escopo de pessoas que podem ter a criatividade estimulada. A questão é como isso deve ser abordado. Para Cropley e Cropley (2009), o treinamento da criatividade em pessoas pode ser (1) focado em potenciais criativos, com eliminação dos "bloqueadores" que inibem a expressão; e (2) focado no que as pessoas ainda não possuem e ajudá-las a adquiri-los.

Qualquer uma das abordagens faz com que as pessoas tenham maior consciência daquilo que pode criar, ou seja, "a auto percepção de criatividade pode influenciar a criatividade de um indivíduo" (LIN et al., 2013, p. 201). Com a criatividade como uma competência estimulada tem-se, então, a promoção de mais indivíduos confiantes e persistentes, que apresentam soluções criativas paras os desafios que são lançados.

\section{Criatividade e Aprendizado}

A criatividade desenvolvida nas pessoas pode estimular o aprendizado, e para que este seja eficiente, é importante que se conheça como ele ocorre.

Segundo Norman (2008), tudo o que fazemos tem um componente cognitivo e afetivo. Cognitivo para atribuir significado, já o afetivo para atribuir valor. O estado afetivo muda a maneira como pensamos. Há duas formas: positivo e negativo. $\mathrm{Na}$ qualidade positiva, possibilita ao indivíduo maior receptividade e dedicação às novas ideias. A curiosidade é despertada pelo estado de afeto positivo, envolvendo a criatividade e tornando o cérebro um organismo eficiente de aprendizado. No estado negativo, o aprendizado é focado na exata resolução do problema, sem distrações. Para ilustrar, quem vê mais a floresta do que as árvores, está no estado de afeto positivo, porém no estado de afeto negativo, é exatamente o oposto, o indivíduo se concentra nos detalhes (NORMAN, 2008).
Ambos os estados possuem sua relevância para o fazer criativo e aprendizado. Enquanto o estado de afeto positivo põe o sujeito numa posição mais relaxada para pensar no problema de forma geral e propor soluções, o estado negativo o coloca no nível da ansiedade, porém focado nos detalhes (NORMAN, 2008). No ambiente escolar, esses estados podem ser trabalhados concomitantemente, tanto pela parte perceptiva quanto pela cognitiva. Assim, o potencial da criatividade de estimular o aprendizado pode ser ampliado.

Sabe-se que a escola é onde se passa grande parte da vida e, portanto, ideal para o desenvolvimento do potencial criativo, por meio de professores criativos que, valendo-se da criatividade, podem tornar suas aulas prazerosas e estimuladoras" (OLIVEIRA, 2010, p. 1). Logo, as práticas docentes não devem ser na simples transmissão do conhecimento, mas sim na aprendizagem dos alunos a fim de possibilitar a eles alternativas de soluções para os problemas. A criatividade não deve ser focada apenas no desenvolvimento conceitual, mas nas intenção, planos e valores dos alunos na resolução de problemas. Essa é uma aprendizagem que visa os interesses dos alunos, na medida em que foca na contextualização, competências cognitivas e interpessoais. Nesse entendimento, a escola pode maximizar as oportunidades de expressão da criatividade nos processos de ensino aprendizagem (BACHERT et al., 2011).

Como todos os indivíduos podem ser encorajados a serem criativos (CROPLEY; CROPLEY, 2009), essa relação criatividade/aprendizado cresce à medida em que se trabalha com grupos maiores, como os de salas de aula.

\subsection{Aprender Coletivo e Criativo}

No processo criativo, a colaboração tem papel relevante para a construção do conhecimento na educação, trazendo novas visões e perspectivas para a resolução de problemas. Juntas, as pessoas podem apresentar soluções mais adequadas para um problema em comum, uma vez que partilham questões, cooperam e interagem com objetivos iguais (BUENO; PADOVANI, 2015). 


\section{$16^{\circ}$ \\ ERGODESIGN USIHC CINAHPA}

De forma similar, nos cursos de artes, há a presença de atividades coletivas. Nesse enfoque, circunscreve-se o presente estudo, envolvendo a condução de uma disciplina no curso de Artes Visuais, do Instituto Federal do Maranhão, com duas turmas de ensino médio-tecnológico.

A produção de gravuras dentro dos ateliês, se divide entre diferentes estágios do fazer, iniciando pela criação dos desenhos, passando pela sua transferência e o entalhe na matriz, seguindo para as impressões, e por fim, a limpeza dos equipamentos e do espaço. Todos esses estágios estão interligados e exigem a discussão coletiva para alinhar todo o processo.

Porém, antes de adentrar no ateliê, é fundamental que todos os envolvidos estejam conscientes do conhecimento prévio que ali será exigido como pressuposto do fazer. Este conhecimento teórico é iniciado em sala de aula. Logo, a questão que surge é: como compreender tais conhecimentos em sala de aula, de maneira que o conteúdo teórico possibilite, não somente estimular a criatividade coletiva e o prazer que as atividades práticas proporcionam nos cursos de artes, mas também, a aprendizagem efetiva?

Um caminho para encontrar uma resposta pode passar pela compreensão das diferentes formas de aprendizado. Felder e Silverman (1988), classificaram os estilos de aprendizagem em diferentes tipos que podem influenciar a criatividade de diferentes maneiras. Entre eles há o estilo visual ou verbal. Este estilo de aprendizagem está relacionado à criatividade (LIN et al., 2013), podendo ser operacionalizado por meio de mensagens visuais.

No contexto educacional, diferentes técnicas de representação gráfica são utilizadas para dimensionar esse estilo de aprendizagem dos alunos (MACHADO et al., 2015). Entre eles podese destacar a produção de artefatos cognitivos, como as Representações Gráficas de Síntese (RGSs), como serão discutidas a seguir. $16^{\circ}$ Ergodesign - Congresso Internacional de Ergonomia e Usabilidade de Interfaces Humano Tecnológica: Produto, Informações Ambientes Construídos e Transporte

$16^{\circ}$ USIHC - Congresso Internacional de Ergonomia e Usabilidade de Interfaces Humano Computador

CINAHPA | 2017 - Congresso Internacional de Ambientes Hipermídia para Aprendizagem.

\section{Representações Gráficas de Síntese}

Representações Gráficas de Síntese - RGSs, são entendidas como artefatos cognitivos, um dispositivo artificial "projetado para manter, apresentar ou operar informação, e que cumpre uma função comunicacional" (BUENO; PADOVANI, 2015, p. 375-376; NORMAN, 1991). No mesmo sentido, Padovani (2012) argumenta que as RGSs são artefatos visíveis bidimensionais estáticos criados com o objetivo de complementar a informação escrita. Elas fazem uso direto da linguagem visual, que são compostas basicamente por: imagens, palavras e formas (HORN, 1998).

Tomando como base a tipologia definida por Fish e Scrivener (1990), pode-se afirmar que, as RGSs são as representações que fazem ponte entre $o$ abstrato e o categórico; e o concreto e o espacialmente específico, ou seja, não são desenhos abstratos, mas também não tem como objetivo serem muito elaborados ou visarem o desenho realista.

O desafio e o objetivo com as RGSs é conseguir sintetizar e organizar as informações para que posteriormente sejam apresentadas visualmente para o público, tornando o conhecimento mais acessível.

Seus resultados podem ser melhor alcançados se trabalhados coletivamente, uma vez que seu fazer criativo coloca os estudantes numa posição maior de conflitos e autonomia sobre os conteúdos que são discutidos, proporcionando maior escuta e lembrança das questões, em um fazer eficiente e agradável (TVERSKY; SUWA, 2009; BUENO; PADOVANI, 2009). Outra questão, é que o fazer colaborativo é importante porque ninguém compreende igual a ninguém: cada um capta partes diferentes do conteúdo igualmente importantes, e assim tem-se o todo mais robusto.

Como os ambientes educacionais ampliam o potencial criativo e de aprendizado, as RGSs ajudam a consolidar esse potencial, já que encontram um lugar propício para serem aplicadas na medida em que proporcionam aos alunos a reflexão coletiva crítica dos assuntos em pauta 


\section{$16^{\circ}$ \\ ERGODESIGN USIHC CINAHPA}

$16^{\circ}$ Ergodesign - Congresso Internacional de Ergonomia e Usabilidade de Interfaces Humano Tecnológica: Produto, Informações Ambientes Construídos e Transporte

$16^{\circ}$ USIHC - Congresso Internacional de Ergonomia e Usabilidade de Interfaces Humano Computador

CINAHPA | 2017 - Congresso Internacional de Ambientes Hipermídia para Aprendizagem.

(BUENO; PADOVANI, 2015).

\subsection{Pensamento Visual}

As RGSs estimulam os indivíduos a trabalharem com representações visuais em duas condições de aprendizado: uma no lado criativo, onde o lado perceptivo é mais exigido; e a outra no lado reflexivo, onde o lado cognitivo é acionado. Sendo assim, RGSs são os instrumentos que irão não apenas auxiliar e estimular a criatividade dos alunos, mas também dar condições de aprendizagem consistente.

Devido a isso, esses artefatos são resultados de um processo criativo chamado Visual Thinking, que estimula os indivíduos a pensar visualmente as questões que são apresentadas. Nela, os participantes do processo são estimulados a pensar tanto com a mente quanto com os olhos, colaborado pelo processo metacognitivo, ou seja, pela auto-regulagem do aprendizado. Assim, as ideias são captadas, pensamentos e dados são sintetizados e organizados, para posteriormente serem materializados graficamente, para exposição do conhecimento ao público.

Essa forma de proceder é sistematizada por Cyrs (1997, apud BUENO; PADOVANI, 2015). Para ele, o Visual Thinking pode ser dividido em três estruturas cognitivas: imaginar, com identificação dos diferentes papéis, funções e propósitos; visualizar, perceber visualmente essas relações; e design, a representação visual.

As RGSs são produzidas normalmente à mão. De acordo com Mayer (2007), dependendo daquilo que está sendo abordado, elas podem ser: lógicas, metafóricas ou configuracionais. Para fins deste estudo, serão utilizados os tipos metafóricos, onde "os indivíduos utilizam imagens familiares como pontes, funis, montanhas, árvores ou meteorologia para expressar ideias ou insights (BUENO; PADOVANI, 2015, p. 378). A seguir, alguns estudos relacionados.

\subsection{Estudo Relacionados}

O uso e a importância das RGSs tem sido demonstrados em alguns estudos. Bueno e
Padovani (2015), utilizaram as RGSs como estratégia didática a uma prática alternativa metodológica, cujo objetivo esteve focado na aprendizagem significativa de disciplinas teóricas a nível de pós-graduação, pelo princípio de colaboração. Os resultados estão refletidos nos relatos dos participantes, onde comentam que gostariam de proceder dessa forma em outras disciplinas e que as RGSs ajudam a fixar melhor os conteúdos.

Outro exemplo (MACHADO, 2015), propôs a utilização da técnica de facilitação gráfica Pensamento Visual em um estudo de caso, que visou a aquisição e disseminação do conhecimento em uma disciplina do Senac de Porto Alegre. Os resultados demonstraram que os alunos foram capazes de expressar sua compreensão de forma organizada e sintética dos diversos assuntos abordados durante a experiência.

Pfister (2013), investigou a questão representação gráfica e seus principais benefícios a partir do estudo de diferentes autores. Segundo seu levantamento, os benefícios podem ser divididos em três categorias distintas: criação, compartilhamento e documentação. Na criação, alguns contributos listados são: melhora da coerência, integridade e criatividade, ajuda a organizar pensamentos e permite a expressão do vago, do específico e a extração do crucial e relevante. No compartilhamento, tem-se a externalização de ideias e significados e facilita o processamento de informação e comunicação. Por fim, a documentação, que facilita a consulta da informação para análise e uma memória gráfica coletiva para recuperação rápida da informação.

Visando elucidar de forma prática os conceitos apresentados, descreve-se a seguir o procedimento metodológico adotado na pesquisa.

\section{Método de Pesquisa}

A pesquisa foi realizada de forma similar com duas turmas de alunos do $1^{\circ}$ ano do curso técnico de Arte Visuais do Instituto Federal de Educação, Ciência e Tecnologia do Maranhão - IFMA, campus Centro Histórico.
Realização:

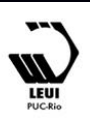




\section{$16^{\circ}$ \\ ERGODESIGN USIHC CINAHPA}

O curso de Artes Visuais, de acordo com o seu plano de curso técnico (LIMA et al., 2009), tem por objetivo "habilitar profissionais em Artes Visuais para atuação nos diferentes níveis e modalidades de criação, produção, fomento e divulgação das artes imagéticas". Entre as disciplinas que compõe a grade curricular, Fundamentos do Desenho e da Gravura tem por objetivo geral "Conhecer as técnicas, materiais e suportes específicos das linguagens do desenho e da gravura, assim como os principais artistas relacionados".

O segundo semestre é dedicado ao módulo da gravura. No entanto, o estágio inicial é dedicado à parte teórica, onde o aluno compreende a linguagem como descrita no objetivo geral da disciplina. Nessa etapa, isto é, durante o terceiro bimestre, foram produzidas as RGSs.

\subsection{Participantes e Materiais}

Foram duas turmas de Artes Visuais, uma com 28 alunos (10 homens e 18 mulheres) e outra com 33 alunos (15 homens e 18 mulheres). A faixa etária esteve entre 13 a 16 anos.

Os materiais utilizados para as atividades foram: papel A3, lápis de desenho, lápis de cor, hidrocores, cartões e cola branca.

\subsection{Procedimento}

A metodologia adotou o mesmo procedimento para as duas turmas.

Na primeira aula, iniciou-se o diálogo com os alunos sobre a proposta de realizar a etapa teórica com a alternativa de produção de mapas mentais. Então, preparou-se uma breve apresentação em slides abordando o assunto, com exposição de exemplos. Então, foi aberto à turma para decidirem se estavam dispostos a enfrentar o desafio e aceitar a proposta. As duas turmas concordaram.

Assim, o procedimento para a produção das RGSs adotou a seguinte configuração: $16^{\circ}$ Ergodesign - Congresso Internacional de Ergonomia e Usabilidade de Interfaces Humano Tecnológica: Produto, Informações Ambientes Construídos e Transporte

$16^{\circ}$ USIHC - Congresso Internacional de Ergonomia e Usabilidade de Interfaces Humano Computador

CINAHPA | 2017 - Congresso Internacional de Ambientes Hipermídia para Aprendizagem.
Quadro 1: configuração do procedimento adotado

\begin{tabular}{|c|c|c|c|}
\hline \multicolumn{2}{|c|}{ FASE 1} & \multicolumn{2}{|c|}{ FASE 2} \\
\hline ETAPA 1 & ETAPA 2 & ETAPA 1 & ETAPA 2 \\
\hline $\begin{array}{l}\text { Aula 1: } \\
\text { exposição } \\
\text { sobre a técnica } \\
\text { do Pensamento } \\
\text { Visual }\end{array}$ & $\begin{array}{l}\text { Aula 2: } \\
\text { apresentação } \\
\text { das RGSs. } \\
\text { Tema: } \\
\text { Pensamento } \\
\text { Visual }\end{array}$ & $\begin{array}{l}\text { Aulas } 3,4, \\
5 \text { e } 6 \text { : aulas } \\
\text { temáticas }\end{array}$ & $\begin{array}{l}\text { Aula 7: } \\
\text { apresentação } \\
\text { das RGSs. } \\
\text { Exposição e } \\
\text { debates }\end{array}$ \\
\hline
\end{tabular}

Fonte: elaborada pelo autor

O procedimento foi dividido em duas grandes fases, que por sua vez se subdividem cada uma em duas etapas.

Fase 1: Esta fase teve por objetivo possibilitar aos estudantes a compreensão da técnica, com objetivos, desafios, e demais detalhes, para capacitá-los à fase seguinte. Duas etapas compõem essa fase:

Etapa 1: A aula iniciou com uma problematização do tema a partir da imagem mostrada na Figura 1. Após isso, seguiu-se com a aula expositiva que consistiu em como aplicar a técnica, além ainda de referências históricas, conceitos e exemplos. Em seguida, cada aluno precisou construir uma RGS com o tema da aula: Pensamento Visual. Neste sentido, o desafio era sintetizar as principais informações, organizar e representá-las visualmente de acordo com o conteúdo exposto. Foi pedido que trabalhassem na forma metafórica de representação, como definido por Mayer (2007).

Figura 1: Representação para problematização

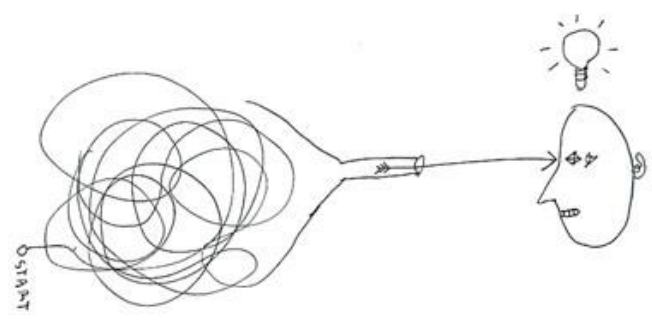

Fonte: xplaner.com (2017)

Etapa 2: na segunda aula, cada aluno apresentou sua RGS em formato A4. Essa etapa consistiu na retirada de dúvidas, para ajustes, esclarecimentos e sugestões. Todas as RGSs foram expostas para a apreciação. Ao final, foi solicitado às turmas que se 


\section{$16^{\circ}$ \\ ERGODESIGN USIHC CINAHPA}

dividissem em equipes com 5 alunos para o próximo desafio: o desenvolvimento coletivo das RGSs em formato A3. A Figura 2 apresenta alguns resultados.

Figura 2: RGSs com o tema Pensamento Visual

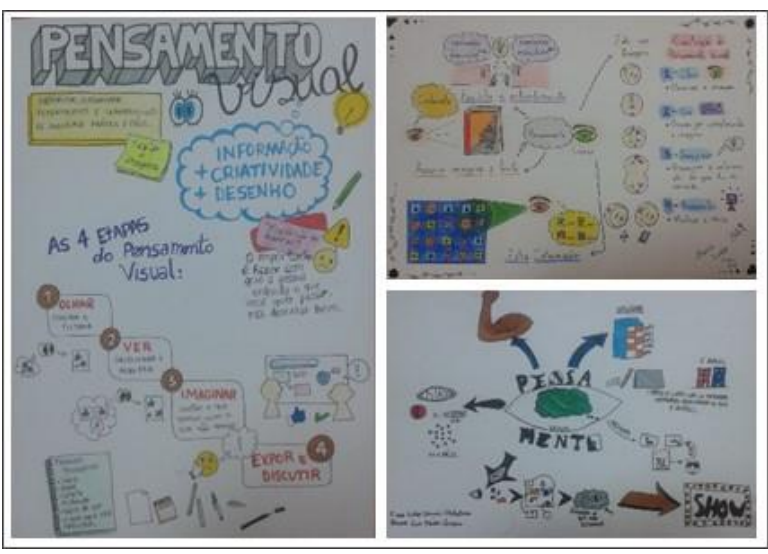

Fonte: produção coletiva dos alunos etapa 1

Fase 2: Principal fase. Teve o objetivo de produzir as RGSs a partir dos conteúdos sobre gravura abordados em sala.

Etapa 1: inicialmente, houve uma breve exposição de como seria conduzida a segunda fase. Em seguida, iniciou-se a exposição do conteúdo teórico que se distribuiu em quatro aulas, com 5 subtemas no total: história, materiais, procedimentos, técnicas e gravadores.

Foi pedido que os alunos apenas anotassem os principais pontos de cada assunto durante as aulas. Após cada aula, as equipes se reuniam para organizar as principais informações apreendidas e iniciar o processo de construção das RGSs de acordo com o tema ora exposto. Somente uma semana depois é que eram disponibilizados os conteúdos dos slides no Google Drive da turma.

Ao final de todo o conteúdo, ou seja, após a conclusão das 4 aulas, cada RGS deveria compreender todos os 5 temas abordados na sala em um único artefato, no formato A2.

Etapa 2: sétima e última aula. Essa etapa consistiu na conclusão das atividades com a apresentação $16^{\circ}$ Ergodesign - Congresso Internacional de Ergonomia e Usabilidade de Interfaces Humano Tecnológica: Produto, Informações Ambientes Construídos e Transporte

$16^{\circ}$ USIHC - Congresso Internacional de Ergonomia e Usabilidade de Interfaces Humano Computador

CINAHPA | 2017 - Congresso Internacional de Ambientes Hipermídia para Aprendizagem.

das RGSs produzidas coletivamente. Teve a característica de seminário, onde foi dada a oportunidade para cada equipe apresentar e defender seu trabalho, e demonstrar o que conseguiram compreender.

Embora cada equipe tenha desenvolvido sua RGS com todos os temas, um tema foi sorteado na hora para que cada uma pudesse abordá-lo na apresentação. Após cada apresentação de tema, o restante da turma foi estimulado ao debate, apresentando complementos, realizando perguntas, fazendo correções, etc., no intuito de retirar os ruídos do conteúdo. As colocações dos alunos foram registradas para composição de nota do semestre. Isso serviu ainda para que a participação deles fosse mais efetiva.

Após todas apresentações, as RGSs foram fixadas para exposição e apreciação de todos, onde foram discutidas as soluções encontradas para cada representação visual.

\section{Resultados e Discussões}

No geral, a satisfação foi grande para todos, uma vez que proporcionou aulas dinâmicas e interativas, estimulando o potencial criativo de todos os envolvidos, e os alunos conseguiram apresentar uma síntese satisfatória daquilo que fora discutido em sala. Isso corresponde a resultados positivos, evidenciando a relevância da estratégia pedagógica adotada na promoção da dimensão cognitiva, perceptiva e afetiva.

É possível inferir que o desenvolvimento da metodologia aplicada permitiu revelar talentos, ratificando o papel central do processo ensino aprendizagem. As atividades desenvolvidas permitiram um mapeamento dos alunos, sendo possível visualizar futuras ações mais pontuais para a proposição de novos estímulos da criatividade, como orienta Cropley e Cropley (2009).

As Figuras 3, 4, 5 e 6 mostram alguns exemplos de RGSs produzidas. 


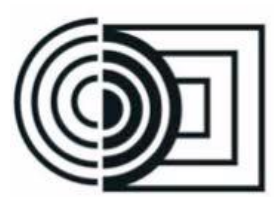

Figura 3: RGSs produzida pela turma

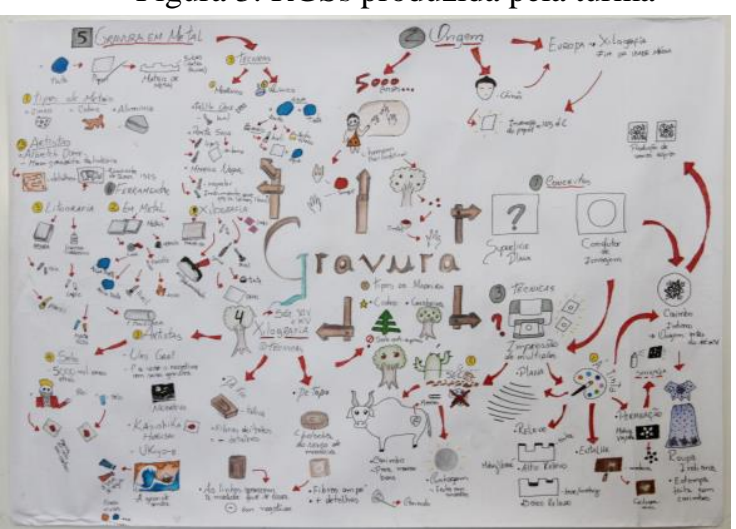

Fonte: produção coletiva dos alunos etapa 1

Embora tenha sido pedido o tipo metafórico para as RGSs, alguns grupos preferiram trabalhar apenas com tipos e gráficos, mas no geral, as equipes optaram por utilizar ilustrações.

Figura 4: RGSs produzida pela turma



Fonte: produção coletiva dos alunos etapa 1

Figura 5: RGSs produzida pela turma

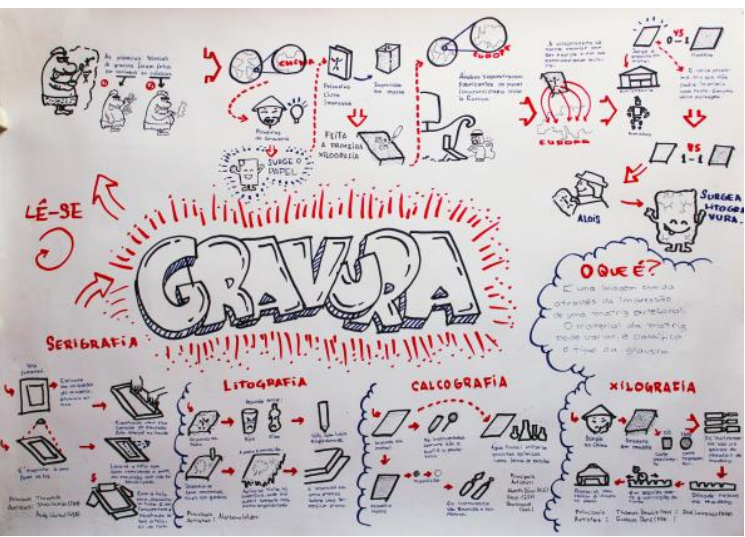

Fonte: produção coletiva dos alunos etapa 1 $16^{\circ}$ Ergodesign - Congresso Internacional de Ergonomia e Usabilidade de Interfaces Humano Tecnológica: Produto, Informações Ambientes Construídos e Transporte

$16^{\circ}$ USIHC - Congresso Internacional de Ergonomia e Usabilidade de Interfaces Humano Computador

CINAHPA | 2017 - Congresso Internacional de Ambientes Hipermídia para Aprendizagem.

Os debates, por vezes, foram calorosos, principalmente porque haviam questionamentos e discordâncias. O medo de errar proporcionou algumas inseguranças nos estudantes. Morais e Almeida (2016) comentam que para que a criatividade ocorra, é necessário conflitos, valores, riscos e poderes. Assim, entende-se que os conflitos e inseguranças são favoráveis ao processo de aprendizado, pois reflete o envolvimento dos alunos no assunto, onde o professor se posiciona apenas para mediar os embates.

Figura 6: RGSs produzida pela turma



Fonte: produção coletiva dos alunos etapa 1

Alguns relatos dos alunos ilustram a experiência com as RGSs:

"[...] O que me ajudou bastante foi no entendimento da Gravura, posso dizer que o Pensamento Visual foi o ponta pé inicial para o meu conhecimento da Gravura [...]"

"O pensamento visual ajuda e me ajudou na fácil compreensão de determinados conteúdos, pois o pensamento visual, trouxe vários benefícios para mim, dentre eles: uma melhor compreensão de conteúdos; desenvolvimento de desenhos; caminhos para termos ideias criativas"

"O trabalho realizado em sala sobre pensamento visual sobre gravura foi bem interessante e uma forma bem didática de trabalhar. Eu gostei muito inclusive, para mim foi uma experiência nova, e se tiver outras oportunidades, com certeza faria de novo".
Realização:
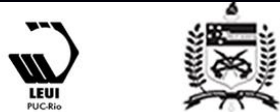


\section{$16^{\circ}$ \\ ERGODESIGN USIHC CINAHPA}

$16^{\circ}$ Ergodesign - Congresso Internacional de Ergonomia e Usabilidade de Interfaces Humano Tecnológica: Produto, Informações Ambientes Construídos e Transporte

$16^{\circ}$ USIHC - Congresso Internacional de Ergonomia e Usabilidade de Interfaces Humano Computador

CINAHPA | 2017 - Congresso Internacional de Ambientes Hipermídia para Aprendizagem.

\begin{abstract}
"A experiência com o Pensamento Visual foi bem interessante porque me permitiu fomentar mais a minha imaginação e trabalhar mais a minha criatividade. [...]. Inclusive, esse método está sendo muito útil agora, porque eu estou fazendo parte do LABDES, que é o Laboratório Social de Design do Desterro, e a gente precisa articular os nossos planos de uma forma bem simplificada e criativa”.
\end{abstract}

Os relatos refletem o lado positivo da experiência de tal maneira que foi possível identificar outras dinâmicas fora da disciplina. Outro professor adotou o método, ainda que de forma assistemática. Uma equipe de alunos decidiu trabalhar a técnica na solução de um trabalho sobre alimentos, na disciplina de Educação Física.

Esses resultados demonstram o valor dessas experiências no ambiente escolar e que se mostrou estimulante e eficaz na prática.

No entanto, algumas limitações foram observadas durante o processo. Algumas delas mostram que é necessário rever o nível do conteúdo da aula introdutória sobre as RGSs, pois como são alunos do $1^{\circ}$ ano, talvez tenha sido um pouco denso para eles. Nas aulas sobre gravura foram utilizados vídeos de apoio e materiais físicos, então a utilização de recursos dessa natureza pode minimizar as dificuldades com o conteúdo sobre as RGSs.

A produção dos alunos sobre cada tema, em horários alternativos fora de sala de aula, é algo a ser pensado. Assim, algumas equipes não tiveram a disciplina de produzir como foi planejado. A sugestão é dividir os horários e pedir para que eles façam isso na segunda parte da aula e em sala. Acredita-se que seja mais interessante porque o conteúdo ainda está claro na mente dos alunos participantes. Vale salientar que, não foi procedido desta forma porque o tempo disponível para apresentar o conteúdo foi escasso e seriam necessárias mais aulas para atender todo o conteúdo programático.

\section{Considerações Finais}

O pensar visual é uma forma característica de pessoas criativas. Logo, o curso de Artes Visuais se configura como um ambiente propício para a aplicação da metodologia focada na aprendizagem dos alunos.

RGSs são meios oportunos para se estimular a criatividade e facilitar o processo de ensino/aprendizagem. Foi observado que esse poder das RGSs se ampliou quando com o trabalho colaborativo, ou seja, por equipes.

O estudo aqui apresentado confirmou que é possível utilizar abordagens alternativas de aprendizado em sala de aula, como as RGSs. Alguns estudantes, inclusive, se sentiram mais motivados e confiantes durante a disciplina, principalmente, aqueles que não possuem afinidade com o curso.

Identificam-se algumas vantagens oferecidas pelo uso das RGSs em sala de aula: elas são uma alternativa à forma tradicional das práticas ensino/aprendizagem, uma vez que elas contribuem para a maior flexibilidade da estrutura curricular e permitem que o estudante aplique suas competências criativas, tornando-o um cidadão crítico, curioso e autorregulado, confiante e motivado. Elas também facilitam a abordagem dos conteúdos teóricos num sentido mais horizontal, uma vez que os alunos também fazem parte das discussões numa postura mais ativa.

Essa flexibilidade no desenho da condução da disciplina deve permitir ao estudante reconhecer, valorizar e aplicar suas competências criativas. Esta foi uma ocorrência durante a experiência, onde o aluno, por meio das RGSs, foi desafiado a apresentar soluções visuais para os conteúdos abordados em sala. Isto proporcionou um encontro entre o aluno e seu potencial criativo dentro do curso de Artes Visuais.

Alguns desdobramentos podem ser realizar a condução alternada de conteúdo e RGS, ou seja, a cada subtema concluído, os alunos devem trazer na aula seguinte suas RGSs e, assim, pequenos 
$16^{\circ}$ Ergodesign - Congresso Internacional de Ergonomia e Usabilidade de Interfaces Humano Tecnológica: Produto, Informações Ambientes Construídos e Transporte

$16^{\circ}$ USIHC - Congresso Internacional de Ergonomia e Usabilidade de Interfaces Humano Computador

CINAHPA | 2017 - Congresso Internacional de Ambientes Hipermídia para Aprendizagem. seminários podem ser realizados. Esta forma pode ser interessante para os alunos já que flexibiliza o andamento das aulas.

Outro estudo futuro pode ser o cruzamento desses aprendizados com as práticas de ateliê. Essa pesquisa é um recorte de parte de uma experiência maior, que tem por objetivo principal facilitar o desenvolvimento das práticas coletivas ocorridas no ateliê de gravura, após os conhecimentos apreendidos durante as atividades de sala de aula.

\section{BIBLIOGRAFIA}

\section{ALENCAR, E. M. L. S. DE. Criatividade no} contexto educacional: três décadas de pesquisa. Psicologia

BACHERT, C. M. D’Antona, DAMASCENO, Y. S. L., NAKANO, T. de C., WECHSLER, S. M. Criatividade: desafios ao conceito. In: CONGRESSO INTERNACIONAL DE CRIATIVIDADE E INOVAÇÃO, 1., 2011, Manaus. Anais... Manaus: UFMA, 2011. p. 8 - 28. Disponível em:

$<\mathrm{http} / / /$ www.criabrasilis.org.br/arquivos/pdfs/122 anais_trabalhos_completos.pdf $>$. Acesso em: 28 mar. 2017

BUENO, J.; PADOVANI, S. A importância do processo de design na criação e desenvolvimento de materiais didáticos digitais. 7th CIDI 7th Information Design International Conference, v. 2, n. 2010, p. 243-258, 2015.

\section{CROPLEY, A.; CROPLEY, D. Fostering} creativity: A diagnostic approach for higher education and organizations. n. 2008, p. 1-3, 2009.

MORAIS, M. de F.; ALMEIDA, L. S. Perceções sobre criatividade: Estudo com estudantes do Ensino Superior. v. 29, n. 2, p. 141-162, 2016.

MORAIS, Maria de Fátima. Criatividade: desafios ao conceito. In: CONGRESSO

INTERNACIONAL DE CRIATIVIDADE E INOVAÇÃO, 1., 2011, Manaus. Anais... Manaus: UFMA, 2011. p. 8 - 28. Disponível em: $<\mathrm{http} / / /$ www.criabrasilis.org.br/arquivos/pdfs/122 anais_trabalhos_completos.pdf>. Acesso em: 28 mar. 2017

FELDER R. M.; SILVERMAN, L. K. Learning and teaching styles in engineering education. Engineering Education, 78(7), 674-681. Franken, 1998.

FISH, J., SCRIVENER, S. Amplifying the Mind's Eye: Sketching and Visual Cognition. Leonardo, 23(1), 1990, pp. 117-126.

LIMA, Rosilene de et al. Plano do Curso Técnico em Artes Visuais Integrado ao Ensino Médio. São Luís: IFMA-CCH, 2009. 70 p.

LIN, C. F. et al. Data mining for providing a personalized learning path in creativity: An application of decision trees. Computers and Education, v. 68, p. 199-210, 2013.

HOSSEINI, A. (2011). University student's evaluation of creative education in universities and their impact on their learning. Procedia - Social and Behavioural Sciences, 15, 1806-1812.

MACHADO, G. B. et al. Representação do Conhecimento através de Pensamento Visual: Uma Experiência Em Sala De Aula. p. 91-106, 2015.

MAYER, C. 2007. Hieroglyphen der Psyche: Mit Patientenskizzen zum Kern der Psychodynamik, Schattauer, Berlin

NORMAN, Donald. Design emocional: por que gostamos (ou detestamos) os objetos do dia-a-dia. Rio de Janeiro: Rocco, 2008. 278 p.

OLIVEIRA, Z. M. F. DE. Fatores influentes no desenvolvimento do potencial criativo. Estudos de Psicologia (Campinas), v. 27, n. 1, p. 83-92, 2010.

PFISTER, A. R. 2013. The Benefits of Sketching for Management. Literature Review and Experimental Evaluation. Dissertation of the University of St.Gallen, School of Management.

PORTAL DA REDE FEDERAL. Governo do
Realização:

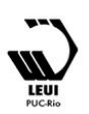




\section{$16^{\circ}$ \\ ERGODESIGN USIHC CINAHPA}

$16^{\circ}$ Ergodesign - Congresso Internacional de Ergonomia e Usabilidade de Interfaces Humano Tecnológica: Produto, Informações Ambientes Construídos e Transporte

$16^{\circ}$ USIHC - Congresso Internacional de Ergonomia e Usabilidade de Interfaces Humano Computador

CINAHPA | 2017 - Congresso Internacional de Ambientes Hipermídia para Aprendizagem.

Brasil. Histórico. 2016. Disponível em:

$<$ http://redefederal.mec.gov.br/historico>. Acesso em: 02 mar. 2016.

TVERSKY, B.,SUWA, M. Thinking with sketches. A. Markman (Editor), Tools for innovation. Oxford: Oxford University Press, 2009.

\section{Agradecimentos}

O desenvolvimento desta pesquisa foi possível devido ao apoio da:

Fundação de Amparo à Pesquisa e ao Desenvolvimento Científico e Tecnológico do Maranhão - FAPEMA e CAPES - Coordenação de Aperfeiçoamento de Pessoal de Nível Superior.

Programa de Pós-Graduação em Design da Universidade Federal do Maranhão - UFMA 